\title{
Facilitating the social participation of pupils with special educational needs in mainstream schools: A review of school-based interventions
}

\author{
Ariana Garrote ${ }^{\mathrm{a}}$, Rachel Sermier Dessemontet ${ }^{\mathrm{b}}, \boldsymbol{\&}$ Elisabeth Moser Opitz $^{\mathrm{a}}$ \\ ${ }^{a}$ University of Zurich, Department of Educational Sciences, \\ Hirschengraben 48, 8001 Zürich, Switzerland \\ ${ }^{\mathrm{b}}$ University of Teacher Education of the CantonVaud, \\ Avenue de Cour 33, 1014 Lausanne, Switzerland
}

Corresponding author: Ariana Garrote (agarrote@ife.uzh.ch)

Co-authors: Rachel Sermier Dessemontet (rachel.sermier@hepl.ch) \& Elisabeth Moser Opitz (emoser@ife.uzh.ch) 


\begin{abstract}
Inclusive education of pupils with special educational needs (SEN) has become a global trend. However, a considerable number of studies have shown that mere enrolment in mainstream classrooms is not enough to support the social participation of pupils with SEN. These children are at risk of experiencing difficulties in their involvement with peers at school. Thus, the question arises of how social participation can be fostered in mainstream classrooms. A systematic review of 35 studies was conducted to investigate which interventions are effective in inclusive mainstream preschool and elementary classrooms. Teaching interaction strategies to typically developing pupils, group activities in the academic context (cooperative learning and peer-tutoring), support groups for pupils with SEN, and training paraprofessionals to facilitate social interactions, were found to improve the social participation of pupils with SEN in general education classrooms. Nevertheless, there is need for more intervention studies implementing a variety of strategies and including different groups of pupils with SEN.
\end{abstract}

Keywords: inclusive classrooms; social interactions; social acceptance; friendship; intervention 


\section{Introduction}

The UN Convention on the Human Rights of Persons with Disabilities guarantees the right of persons with disabilities to an inclusive education system at all levels (United Nations, 2006). As a consequence, in recent decades, inclusive education of pupils with special educational needs (SEN) in mainstream schools has become a global trend (Bless, 2004; Huber 2006; Koster, Nakken, Pijl, \& van Houten, 2009; Pijl, Frostad, \& Flem, 2008; Ruijs \& Peetsma, 2009). Enrolment in mainstream classrooms is meant to give pupils with SEN the opportunity to live and learn next to typically developing (TD) children of the same age and to be considered full members of the classroom and the community. However, many studies reveal that the social participation of pupils with SEN in inclusive classrooms is not optimal and therefore interventions are clearly needed. Yet, sound knowledge on effective teaching practices in this domain is lacking. Our review attempts to fill this gap and provide an overview of the research on the topic. The following question shall be answered: What type of school-based interventions can foster the social participation of pupils with SEN in mainstream preschool and primary classrooms?

Firstly, we describe the results of studies on the social participation of pupils with SEN in general education classrooms. Secondly, we present a systematic review of the research identifying school-based interventions aiming to foster the social participation of children with SEN in general education classrooms. Compared to other reviews and meta-analyses published up to the present, which focus on a specific group of children with SEN, mainly children with autism spectrum disorders (ASD), this study takes into account all pupils with SEN (e.g., children with learning disabilities, intellectual disability, ASD, and behavioural difficulties). In addition, while the previous reviews and meta-analyses describe only studies published in English, our systematic research also considers studies in German and French.

\subsection{Social participation of SEN pupils in inclusive classrooms}

The concept of social participation usually involves the aspects of engagement in activities, feelings of belonging, and social interactions (Eriksson \& Granlund, 2004; Falkmer, Granlund, Nilhom, \& Falkmer, 2012; Hammel et al., 2008). The concept can be defined in many different ways, however, depending on the context (e.g., school, leisure, professional life; Bossaert, Colpin, Pijl, \& Petri, 2013; Falkmer et al., 2012; Simeonsson, Carlson, Huntington, Sturtz McMillen, \& Brent, 2001). In the context of inclusive primary school, Koster and her colleagues (2009) carried out a review of the literature to evaluate the definitions used in different studies to describe the social participation of pupils with SEN included in mainstream classrooms. They identified four dimensions of social participation in inclusive classrooms: (1) the acceptance of pupils with SEN, (2) the pupils' perceptions of their acceptance by the classmates, (3) the presence of positive social interactions between pupils with SEN and their classmates, and (4) social relationships/friendships. Intuitively, the social interactions between pupils with SEN and their classmates can be regarded as the most essential dimension for social participation. Without social interactions with classmates, it is technically impossible for pupils with SEN to build friendships or to be socially accepted by them. Further, social acceptance not only manifests itself within social interactions, but can also facilitate social interactions and consequently the creation of friendships. From the individual perspective, feeling accepted by peers and having friends is important for positive experiences in social participation. In the following section, the research on the social participation of pupils with SEN will be described along these four dimensions. 


\subsubsection{Social acceptance of pupils with SEN}

The most studied dimension of social participation is the social acceptance of pupils with SEN. A majority of the studies show that pupils with SEN included in preschool or primary classrooms are more often rejected and less well accepted by their peers than TD pupils (Avramidis, 2013; Cambra \& Silvestre, 2003; Estell et al., 2008; Frederickson, Simmonds, Evans, \& Soulsby, 2007; Freeman \& Alkin, 2000; Garrote, 2016; Grütter, Meyer, \& Glenz, 2015; Hestenes \& Carroll, 2000; Huber \& Wilbert, 2012; Koster, Pijl, Nakken, \& van Houten, 2010; Krull, Wilbert, \& Henneman, 2014; de Monchy, Pijl, \& Zandberg, 2004; Nadeau \& Tessier, 2003; Nowicki, 2003; Nepi, Fioravanti, Nannini, \& Peru, 2015; Odom \& Diamond, 1998; Pijl \& Frostad, 2010; Pijl, Skaalvic, \& Skaalvic, 2010; Rotheram-Fuller, Kasari, Chamberlain, \& Locke, 2010; Yude, Goodman, McConachie, 1998). This is the case not only during recess but also in the classroom (Cambra \& Silvestre, 2003; Frederickson et al., 2007). TD pupils in primary schools prefer not to work with pupils with SEN or with low-achieving pupils (Huber \& Wilbert, 2012; Krull et al., 2014; de Monchy et al., 2004). These findings mean that achievement plays an important role regarding the acceptance of pupils in primary school. Additionally, social acceptance by peers depends on the social behaviour of children with SEN (Avramidis, 2013; Huber \& Wilbert, 2012; Pijl et al., 2008; Schwab, Gebhardt, Krammer, \& GasteigerKlicpera, 2015). Thus, pupils with behavioural difficulties (BD) are at greater risk of being rejected by their peers than pupils with learning disabilities (LD) or motor and/or sensory disabilities (Avramidis, 2010; Krull et al., 2014; Pijl et al., 2008).

\subsubsection{Self-perception of SEN pupils of their social acceptance}

Findings are more ambivalent regarding the pupils' perception of their social acceptance. Some studies involving 6- to 9-year-old pupils with SEN show that their perception of social acceptance does not differ from the perception of their peers, who are more accepted (Koster et al., 2010; Krull et al., 2014). Studies involving older pupils with SEN found that these pupils feel less socially accepted and report more feelings of loneliness than their TD peers (Cambra \& Silvestre, 2003; Schwab et al., 2015). Nevertheless, altogether, the SEN pupils' self-perception of social acceptance is positive, even if their real social acceptance in the classroom is low (Avramidis, 2013, Cambra \& Silvestre, 2003; Koster et al., 2010; Krull et al., 2014; Schwab et al., 2015). The question arises as to whether other aspects of social participation, such as being involved in social interactions or having friends, may have an effect on the pupils' self-perception of social acceptance. Indeed, friendships can have a positive influence on the socio-emotional development of children (Gifford-Smith \& Brownell, 2003) and can reduce the negative impact of social rejection (Peters, Riksen-Walraven, Cillessen, \& de Weerth, 2011; Hodges, Boivin, Vitaro, \& Bukowski; 2011).

\subsubsection{Social interactions between pupils with and without SEN}

Only a few studies have focused on social interactions; however, they show consistently that pupils with SEN are less involved in social interactions with their peers than their TD classmates in preschool and primary school. This has been especially shown for pupils with ASD, intellectual disability (ID), and Down syndrome (Hestenes \& Carroll, 2000; Kasari, Locke, Gulsrud, \& Rotheram-Fuller, 2011; Kemp \& Carter, 2002; Koster et al., 2010; Scheepstra, Nakken, \& Pij1, 1999). Studies on the social interactions of other groups of pupils with SEN are lacking. Extending knowledge on this dimension of social participation is important because a lack of interactions often leads to an inability to create stable social relationships and friendships. 


\subsubsection{Friendships and social relationships of pupils with SEN}

The findings regarding the social relationships and friendships of pupils with SEN in inclusive classrooms are not very clear. Many studies have shown that pupils with SEN included in preschool and primary school have fewer friends than their TD peers (Avramidis, 2013; Estell et al., 2008; Frostad \& Pijl, 2007; Koster et al., 2010; Odom \& Diamond, 1998; Pijl et al., 2008; Rotheram-Fuller et al., 2010; Yude et al., 1998); however, other studies have not found this difference (Avramidis, 2010; Garrote, 2016; Grütter et al., 2015; Walker, 2007). Clearly, more studies are needed to investigate which factors might facilitate the creation and maintenance of social relationships and friendships in some cases, but not in others.

\subsection{Implemented interventions}

Pupils with SEN included in mainstream classrooms seem to be at risk of experiencing difficulties in their social participation. This raises questions about the implementation of the interventions and the framework conditions. Historically, the first approach that was investigated involved teaching social skills to children with SEN (Bierman \& Powers, 2009). Several meta-analyses have shown, however, that these interventions have rather weak effects on the social skills of pupils with LD, ASD or BD, and on their social acceptance in class (Bellini, Peters, Benner, \& Hopf, 2007; Kavale \& Forness, 1996; Kavale \& Mostert, 2004; Quinn, Kavale, Mathur, Rutherford, \& Forness, 1999). These rather deceiving results could be because the evaluated interventions were often implemented separately from the natural context of the children, for example, in clinical settings or pull-off resources (Bellini et al., 2007; Kavale \& Forness, 1996; Quinn et al., 1999). Therefore, it is possible that pupils with SEN could not transfer the learned social skills into a natural context with their peers. In addition, focusing exclusively on children with SEN and not involving their TD peers in the interventions may not help to change the latter's perception and behaviour towards pupils with SEN (Soodak \& McCarthy, 2006).

Up to the present, the reviews and meta-analyses evaluating the effects of interventions with dependent variables other than the social skills of pupils with SEN have focused only on one or two dimensions of social participation, social interactions and social relationships/friendships (e.g., Camargo et al., 2014; McConnell, 2002; Whalon, Conroy, Martinez, \& Werch, 2015). There is clearly a need for reviews using a broader definition of the concept of social participation, involving the evaluation of interventional effects not only on social interactions but also on the social acceptance, perceived social acceptance, and social relationships/friendships of pupils with SEN. This systematic review aims to identify and describe different studies evaluating the effect of interventions developed to foster the social participation of pupils with SEN in preschool and primary mainstream classrooms.

\section{Methodology}

This review involves studies on the topic published between January 1990 and June 2016 in the databases PsycINFO, PSYINDEX, ERIC, FIS Bildung, and FRANCIS searched with the key words inclusive education or inclusion, combined with the key words social participation or its dimensions (social relationships/friendships, social interactions, social acceptance, social self-concept/social self-perception), as well as different key words used to designate pupils having special educational needs (e.g., learning disability, language disability, behavioural disorders/problems, intellectual disability, visual impairment, 
hearing impairment, motor impairment, and autism). The key words were entered in English, German, and French. Only journal contributions were included. Figure 1 shows the number of identified and selected records.

\section{Figure 1}

Flowchart of the search for and inclusion of studies

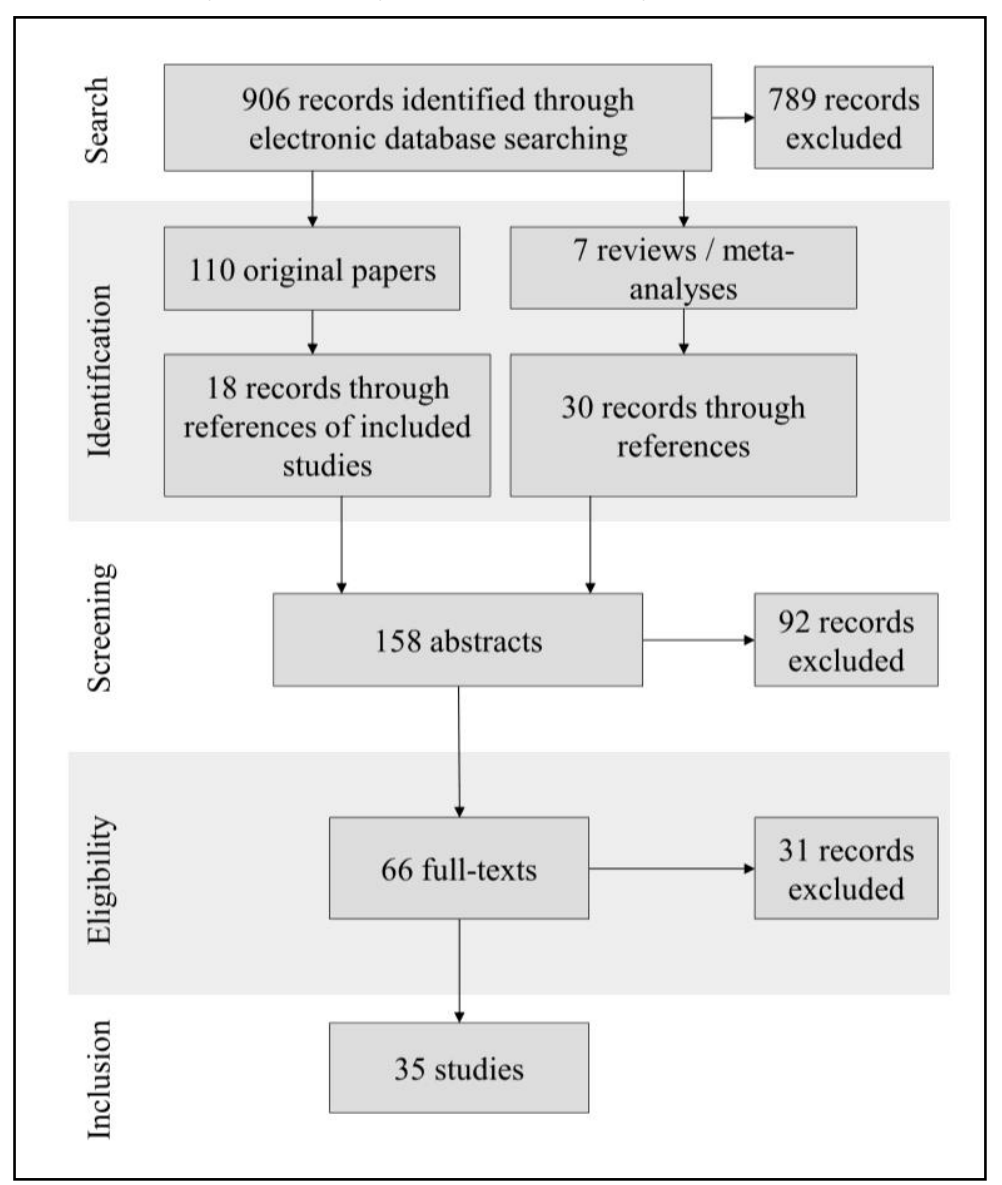

In a first step, records identified through the database search were selected if their titles matched the topic of interest. In a second step, the references of selected records, as well as of meta-analyses and reviews on the topic were searched for further records. The third step consisted of screening the abstracts of the selected records and excluding them if they did not meet the selection criteria. Finally, the full-text articles were assessed for eligibility. The articles were included in the review only if they corresponded to the following selection criteria. (a) The study evaluated the effects of school-based interventions aiming to foster the social participation of children with SEN in mainstream preschools or primary classrooms. (b) All participating pupils with SEN were full-time members of a general education classroom. (c) The study had an experimental, a quasi-experimental, or a single-case experimental design. (d) The study was published in a peer-reviewed journal.

A total of 66 articles seemed to correspond to the criteria according to the titles and abstracts. Among these articles, 31 were excluded after reading the content, in several cases because the pupils with SEN were enrolled in special education or self-contained classrooms and were therefore not full-time members of a 
general education classroom with TD peers (e.g., Hartzell, Gann, Liaupsin, \& Clem, 2015; Hundert, Rowe, \& Harrison, 2014; McFadden, Kamps, \& Heitzman-Powell, 2013; Stanton-Chapman \& Brown, 2015; Stanton-Chapman \& Snell, 2011). No studies in French or German fulfilled the criteria. The study of Kamps et al. (2002) fulfilled all criteria, but was excluded because the results were also reported in Kamps et al. (1992) and Kamps, Barbetta, Leonard, and Delquadri (1994). A final total of 35 articles were selected for the review, 14 of which were found in the reviews of Camargo et al. (2014), Chang and Locke (2016), Harrower and Dunlap (2001), and Watkins et al. (2015).

\section{Results}

Of the 35 selected studies, 14 evaluate school-based interventions taking place in preschool settings, 15 in primary schools and six in preschool and primary schools. The detailed content of the studies is summarized in tables 1,2, and 3. In the following sections, the interventions are described based on the type of schoolbased intervention. Three intervention types were identified: teaching interaction strategies (table 1), group activities (table 2), and training of paraprofessionals (table 3). More than half of the studies $(n=19)$ measure the effects of teaching interaction strategies to pupils on the social interactions among them. A third of the studies $(n=12)$ measure the effects of group activities. A minority of the studies $(n=4)$ measure the effects of training paraprofessionals with the goal to increase the frequency of social interactions between pupils with SEN and their peers. The intervention effects are reported in relation to the four dimensions of social participation (friendships, social interactions, social acceptance, and perceived social acceptance). In single case studies, effects are considered positive if a meaningful change in the dependent variable was established for at least three-fourths of the participants, as recommended by the Council for Exceptional Children (2014). Effects are described as mixed if a significant change occurred for less than three-fourths of the participants. For single-case studies, as well as group studies, effects are described as mixed if a positive effect was established when the intervention was implemented, but was not maintained once the intervention was removed. Finally, effects were described as neutral when neither positive, negative or mixed effects were found. Effect sizes were not reported in most studies. When they were reported, different types of effect sizes were used among the group studies (Cohen's $d$ or $\eta^{2}$ ) and the single case studies (percentage of nonoverlapping data or Tau-U). For some of the single-case studies included in this review the effect sizes (nonoverlap of all pairs and Tau- $U$ ) were calculated in the meta-analysis by Whalon et al. (2015). When researchers did not offer an interpretation of effect sizes, the guidelines suggested by Cohen (1988) for group studies and by Scruggs and Mastropieri (1998) for single-case studies were used to categorize effects as small, medium or large. 
Table 1

Articles included in the review: teaching interaction strategies

\begin{tabular}{|c|c|c|c|c|c|c|}
\hline Authors (year) & $\begin{array}{l}\text { Target pupils } \\
\text { (number, age) }\end{array}$ & Intervention & Involved pupils & Implementation & Measures & Effect \\
\hline Banda et al. (2010) & $\operatorname{ASD}(n=2 ; 6 y)$ & $\begin{array}{l}\text { Interaction strategies to SEN pupils } \\
\text { and peers }\end{array}$ & Entire class & Teachers & Interactions & + \\
\hline $\begin{array}{l}\text { Batchelor \& Taylor } \\
\text { (2005) }\end{array}$ & ID $(\mathrm{n}=1 ; 4 \mathrm{y})$ & $\begin{array}{l}\text { Awareness, interaction strategies, } \\
\text { and social problem solving to peers }\end{array}$ & Entire class & Teacher & $\begin{array}{l}\text { Interactions } \\
\text { Acceptance }\end{array}$ & $\begin{array}{l}+ \\
+\end{array}$ \\
\hline $\begin{array}{l}\text { Goldstein \& Cisar } \\
\text { (1992) }\end{array}$ & $\begin{array}{l}\operatorname{ASD}(\mathrm{n}=2 ; \mathrm{NR}) \\
\mathrm{BD}(\mathrm{n}=1 ; \mathrm{NR})\end{array}$ & Interaction strategies to peers & $\begin{array}{l}\text { Two selected peers } \\
\text { per SEN pupil }\end{array}$ & Teachers & Interactions & + \\
\hline Goldstein et al. (1997) & ID $(n=8 ; 3-5 y)$ & $\begin{array}{l}\text { Awareness and interaction } \\
\text { strategies to peers }\end{array}$ & $\begin{array}{l}\text { One selected peer } \\
\text { per SEN pupil }\end{array}$ & Researchers & $\begin{array}{l}\text { Interactions } \\
\text { Acceptance }\end{array}$ & $\begin{array}{l}+ \\
+\end{array}$ \\
\hline Goldstein et al. (1992) & $\operatorname{ASD}(n=5 ; 2-6 y)$ & Interaction strategies to peers & Entire class & Teachers or researchers & Interactions & + \\
\hline $\begin{array}{l}\text { Harjusola-Webb et al. } \\
\text { (2012) }\end{array}$ & $\operatorname{ASD}(\mathrm{n}=1 ; 5 \mathrm{y})$ & Interaction strategies to peers & Entire class & Teachers & Interactions & + \\
\hline Harper et al. (2008) & $\operatorname{ASD}(\mathrm{n}=2 ; 8-9 \mathrm{y})$ & Interaction strategies to peers & $\begin{array}{l}\text { Six volunteering } \\
\text { peers }\end{array}$ & Researchers & Interactions & + \\
\hline $\begin{array}{l}\text { Hundert \& Houghton } \\
\text { (1992) }\end{array}$ & $\begin{array}{l}\mathrm{DD}(\mathrm{n}=9) \\
\operatorname{BD}(\mathrm{n}=2), \mathrm{HI}(\mathrm{n}=1) \\
\text { VI }(\mathrm{n}=1) ;(3-5 y)\end{array}$ & $\begin{array}{l}\text { Interaction strategies to SEN pupils } \\
\text { and peers }\end{array}$ & Entire class & Therapists and teachers & $\begin{array}{l}\text { Interactions } \\
\text { Acceptance }\end{array}$ & $\begin{array}{l}\text { mixed } \\
\text { neutral }\end{array}$ \\
\hline Kamps et al. (2015) & $\operatorname{ASD}(n=95 ; 6-8 y)$ & $\begin{array}{l}\text { Interactions strategies to SEN } \\
\text { pupils and peers }\end{array}$ & $\begin{array}{l}\text { Four to six selected } \\
\text { peers per SEN pupil }\end{array}$ & $\begin{array}{l}\text { Speech language } \\
\text { pathologists, } \\
\text { paraprofessionals, } \\
\text { special education } \\
\text { teachers, or counsellors }\end{array}$ & Interactions & + \\
\hline
\end{tabular}


Articles included in the review: teaching interaction strategies

\begin{tabular}{|c|c|c|c|c|c|c|}
\hline Authors (year) & $\begin{array}{l}\text { Target pupils } \\
\text { (number, age) }\end{array}$ & Intervention & Involved pupils & Implementation & Measures & Effect \\
\hline Kamps et al. (1992) & $\operatorname{ASD}(n=3 ; 7 y)$ & $\begin{array}{l}\text { Interaction strategies to SEN pupils } \\
\text { and peers }\end{array}$ & Entire class & Teacher & Interactions & + \\
\hline $\begin{array}{l}\text { Katz \& Girolametto } \\
(2013)\end{array}$ & $\operatorname{ASD}(\mathrm{n}=3 ; 4-5 \mathrm{y})$ & $\begin{array}{l}\text { Interaction strategies to SEN pupils } \\
\text { and two selected peers }\end{array}$ & $\begin{array}{l}\text { Two peers per SEN } \\
\text { pupil }\end{array}$ & Teachers & Interactions & + \\
\hline Kohler et al. (2007) & $\operatorname{ASD}(\mathrm{n}=1 ; 4 \mathrm{y})$ & Interaction strategies to peers & Six peers & Teacher & Interactions & + \\
\hline Mason et al. (2014) & $\operatorname{ASD}(\mathrm{n}=3 ; 6-8 \mathrm{y})$ & Interaction strategies to peers & $\begin{array}{l}\text { Four to six selected } \\
\text { peers per SEN pupil }\end{array}$ & $\begin{array}{l}\text { Speech language } \\
\text { pathologist, } \\
\text { paraprofessional, or } \\
\text { researcher }\end{array}$ & Interactions & + \\
\hline McGrath et al. (2003) & $\operatorname{ASD}(\mathrm{n}=1 ; 4 \mathrm{y})$ & $\begin{array}{l}\text { Interaction strategies to six selected } \\
\text { peers }\end{array}$ & Entire class & Researcher & Interactions & + \\
\hline Nelson et al. (2007) & $\operatorname{ASD}(n=4 ; 3-4 y)$ & $\begin{array}{l}\text { Interaction strategies to SEN pupils } \\
\text { and peers }\end{array}$ & Entire class & Research assistants & Interactions & + \\
\hline $\begin{array}{l}\text { Owen-De Schryver et al. } \\
\text { (2008) }\end{array}$ & $\operatorname{ASD}(\mathrm{n}=3 ; 7-10 \mathrm{y})$ & $\begin{array}{l}\text { Awareness and interaction } \\
\text { strategies to peers }\end{array}$ & $\begin{array}{l}\text { Two to four selected } \\
\text { peers per SEN pupil }\end{array}$ & Researchers & Interactions & + \\
\hline $\begin{array}{l}\text { Pierce \& Schreibman } \\
\text { (1997) }\end{array}$ & $\operatorname{ASD}(\mathrm{n}=2 ; 7-8 \mathrm{y})$ & Interaction strategies to peers & Six peers & NR & Interactions & + \\
\hline Storey et al. (1993) & $\mathrm{DD}(\mathrm{n}=8 ; 4 \mathrm{y})$ & Interaction strategies to peers & $\begin{array}{l}\text { Two selected peers } \\
\text { per SEN pupil }\end{array}$ & Classroom assistants & Interactions & + \\
\hline $\begin{array}{l}\text { Thiemann \& Goldstein } \\
\text { (2004) }\end{array}$ & $\operatorname{ASD}(\mathrm{n}=5 ; 6-9 y)$ & Interaction strategies to peers & $\begin{array}{l}\text { Two selected peers } \\
\text { per SEN pupil }\end{array}$ & $\begin{array}{l}\text { Teachers and/or } \\
\text { researchers }\end{array}$ & $\begin{array}{l}\text { Interactions } \\
\text { Acceptance }\end{array}$ & $\begin{array}{l}+ \\
+\end{array}$ \\
\hline
\end{tabular}

$\mathrm{DD}=$ developmental delays, $\mathrm{HI}=$ hearing impairment, $\mathrm{NR}=$ not reported, $\mathrm{VI}=$ visual impairment 
Table 2

Articles included in the review: group activities

\begin{tabular}{|c|c|c|c|c|c|c|}
\hline Authors (year) & $\begin{array}{l}\text { Target pupils } \\
\text { (number, age) }\end{array}$ & Intervention & Involved pupils & Implementation & Measures & Effect \\
\hline Dugan et al. (1995) & $\operatorname{ASD}(n=2 ; 9-10 y)$ & Cooperative learning & Entire class & $\begin{array}{l}\text { Teacher and } \\
\text { paraprofessional }\end{array}$ & Interactions & + \\
\hline Frea et al. (1999) & $\mathrm{DD}(\mathrm{n}=2 ; 4 \mathrm{y})$ & $\begin{array}{l}\text { Structured play and } \\
\text { friendship activities }\end{array}$ & Entire class & Teachers & Interactions & mixed \\
\hline $\begin{array}{l}\text { Frederickson \& Turner } \\
\text { (2003) }\end{array}$ & $\mathrm{BD}(\mathrm{n}=20 ; 6-12 \mathrm{y})$ & Circle of Friends & $\begin{array}{l}\text { Four to eight selected peers } \\
\text { per circle }\end{array}$ & $\begin{array}{l}\text { Research assistants } \\
\text { and teachers }\end{array}$ & $\begin{array}{l}\text { Acceptance } \\
\text { Perceived } \\
\text { acceptance }\end{array}$ & $\begin{array}{l}+ \\
\text { neutral }\end{array}$ \\
\hline Frederickson et al. (2005) & $\begin{array}{l}\operatorname{ASD}(n=1) \\
\operatorname{BD}(n=6) \\
\operatorname{LD}(n=7) ;(6-11 y)\end{array}$ & Circle of Friends & $\begin{array}{l}\text { Six to eight volunteer peers } \\
\text { per circle }\end{array}$ & $\begin{array}{l}\text { Assistant } \\
\text { educational } \\
\text { psychologist }\end{array}$ & Acceptance & mixed \\
\hline Fuchs et al. (2002) & $\operatorname{LD}(\mathrm{n}=25 ; 8-11 \mathrm{y})$ & Peer tutoring & Entire class & Teachers & $\begin{array}{l}\text { Acceptance } \\
\text { (Friendship)* }^{*}\end{array}$ & + \\
\hline Hunt et al. (1997) & $\begin{array}{l}\operatorname{ASD}(\mathrm{n}=1 ; 10 \mathrm{y}), \\
\operatorname{DD}(\mathrm{n}=1 ; 5 \mathrm{y}) \\
\operatorname{ID}(\mathrm{n}=1 ; 10 \mathrm{y})\end{array}$ & $\begin{array}{l}\text { Multi-component } \\
\text { intervention }\end{array}$ & Entire class & $\begin{array}{l}\text { Teachers, speech } \\
\text { language therapists, } \\
\text { and researchers }\end{array}$ & Interactions & + \\
\hline Jacques et al. (1998) & ID $(n=24 ; 9-11 y)$ & Cooperative learning & Entire class & Researcher & Acceptance & + \\
\hline $\begin{array}{l}\text { Kalyva \& Avramidis } \\
(2005)\end{array}$ & $\operatorname{ASD}(n=5 ; 3-4 y)$ & Circle of Friends & Five selected peers per circle & Teacher & Interactions & + \\
\hline Kamps et al. (1994) & $\operatorname{ASD}(\mathrm{n}=3 ; 8-9 y)$ & Peer tutoring & Entire class & $\begin{array}{l}\text { Researchers and } \\
\text { teachers }\end{array}$ & Interactions & + \\
\hline Koegel et al. (2012) & $\operatorname{ASD}(n=3 ; 9-12 y)$ & Interest clubs & $\begin{array}{l}\text { Six to ten volunteer peers per } \\
\text { club }\end{array}$ & Research assistants & Interactions & + \\
\hline
\end{tabular}


Articles included in the review: group activities

\begin{tabular}{|c|c|c|c|c|c|c|}
\hline Authors (year) & $\begin{array}{l}\text { Target pupils } \\
\text { (number, age) }\end{array}$ & Intervention & Involved pupils & Implementation & Measures & Effect \\
\hline $\begin{array}{l}\text { Shechtman (1999), } \\
\text { elementary pupils }\end{array}$ & $\mathrm{BD}(\mathrm{n}=112 ; \mathrm{NR})$ & $\begin{array}{l}\text { Therapeutic group } \\
\text { counselling }\end{array}$ & Entire class & Teachers & $\begin{array}{l}\text { Acceptance } \\
\text { Perceived } \\
\text { acceptance }\end{array}$ & $\begin{array}{l}\text { neutral } \\
\text { neutral }\end{array}$ \\
\hline Sideridis et al. (1997) & $\begin{array}{l}\operatorname{ID}(n=1 ; 13 y) \\
\operatorname{LD}(n=2 ; 12-13 y)\end{array}$ & Peer tutoring & Entire class & Teacher & Interactions & + \\
\hline
\end{tabular}

*Friendships were only measured after the intervention

Table 3

Articles included in the review: training of paraprofessionals

\begin{tabular}{|c|c|c|c|c|c|c|}
\hline Authors (year) & $\begin{array}{l}\text { Target pupils } \\
\text { (number, age) }\end{array}$ & Intervention & Involved pupils & Implementation & Measures & Effect \\
\hline Feldman \& Matos (2012) & $\operatorname{ASD}(\mathrm{n}=3 ; 5-8 \mathrm{y})$ & Facilitating interactions & Entire class & Paraprofessionals & Interactions & + \\
\hline Kretzmann et al. (2015) & $\operatorname{ASD}(\mathrm{n}=24 ; 6-11 \mathrm{y})$ & Facilitating interactions & Peers at recess & Paraprofessionals & Interactions & + \\
\hline Licciardello et al. (2008) & $\operatorname{ASD}(n=4 ; 6-8 y)$ & Facilitating interactions & Peers at recess & Paraprofessionals & Interactions & + \\
\hline Malmgren et al. (2005) & $\mathrm{BD}(\mathrm{n}=3, \mathrm{NR})$ & Facilitating interactions & Entire class & Paraprofessionals & Interactions & mixed \\
\hline
\end{tabular}




\subsection{Teaching interaction strategies}

Almost all of the studies measuring the effects of teaching interaction strategies to pupils are single case studies. Only one study is an experimental study with control group (Kamps et al., 2015). In most of the studies, interaction strategies were only taught to TD pupils. In other cases, both, pupils with SEN and their TD peers, learned strategies to communicate with each other. A majority of interventions were implemented by teachers alone or in collaboration with the researchers.

Participants: The 19 studies included 163 pupils with SEN, aged 2 to 10 years. The number of participants per study varies from one to 95 . The majority of the pupils $(n=132)$ were diagnosed with ASD. Nine participants had ID, 17 pupils had a developmental delay (DD), three had BD, one had a hearing impairment, and one had a visual impairment.

Interventions: Thirteen studies evaluated the effects of teaching interaction strategies to TD peers to increase or improve their social interactions with pupils with ASD, BD, DD, or ID (Batchelor \& Taylor, 2005; Goldstein \& Cisar, 1992; Goldstein, Kaczmarek, Pennington, \& Shafer, 1992; Goldstein, English, Shafer, \& Kaczmarek, 1997; Harjusola-Webb, Hubbell, \& Bedesem, 2012; Harper, Symon, \& Frea, 2008; Kohler, Greteman, Raschke, \& Highnam, 2007; Mason et al., 2014; McGrath, Bosch, Sullivan, \& Fuqua, 2003; Owen-DeSchryver, Carr, Cale, \& Blakeley-Smith, 2008; Pierce \& Schreibman, 1997; Storey, Smith, \& Strain, 1993; Thiemann \& Goldstein, 2004). The strategies taught by adults involved mainly the initiation and maintenance of social interactions during episodes of free play (e.g., suggesting games, sharing or exchanging objects, initiating a conversation, making compliments or commenting on an ongoing game). Two studies evaluated the programme "Stay, Play, Talk". In this intervention, selected TD pupils (Goldstein et al., 1997) or all TD classmates (Batchelor \& Taylor, 2005) learned strategies to initiate and maintain interactions with their peers with ID.

In six studies, pupils with ASD, DD, BD, or visual and hearing impairments were also taught how to better interact with their TD peers (Banda, Hart, \& Lui-Gitz, 2010; Hundert \& Houghton, 1992; Kamps et al., 1992; Kamps et al., 2015; Katz \& Girolametto, 2013; Nelson, McDonnell, Johnston, Crompton, \& Nelson, 2007). For example, in the intervention programme "Keys to Play" (Nelson et al., 2007), preschool pupils learned to use a golden key to initiate interactions with their peers with ASD. Pupils with ASD were simultaneously taught by an adult to respond to the visual trigger (golden key) or to initiate a game by using the key as well.

Effects: Almost all the reviewed studies showed positive intervention effects on the social interactions between pupils with ASD, BD, DD, and ID and their TD peers regarding the frequency, duration, and/or quality of the social interactions. Effect sizes were only mentioned by Banda et al. (2010), Katz and Girolametto (2015), and Mason et al. (2014). They reported medium to large effect sizes. In their metaanalysis, Whalon et al. (2015) also reported medium to large effect sizes for some of the single-case studies described in this section (Kohler et al., 2007; Nelson et al., 2007; Owen-DeSchryver et al., 2008; Thiemann \& Goldstein, 2004). Several of these studies show that this positive effect was generalized or maintained once the intervention was removed (Batchelor \& Taylor, 2005; Harper et al., 2008; Kamps et al., 1992; Kamps et al., 2015; Katz \& Girolametto, 2013; Kohler et al., 2007; Nelson et al., 2007; Pierce \& Schreibman, 1997; Thiemann \& Goldstein, 2004). In the only study finding a mixed effect (Hundert \& Houghton, 1992), a meaningful increase in interactions was found during the intervention, but this effect was neither generalized nor maintained once the intervention was removed. 
Three studies found positive effects on the social acceptance of pupils with SEN, regardless of whether all classmates or only some were involved in the intervention, but do not mention effect sizes (Batchelor \& Taylor, 2005; Goldstein et al., 1997; Thiemann \& Goldstein, 2004). Indeed, the study by Thiemann and Goldstein (2004) revealed a positive influence on the TD pupils who did not actively participate in the intervention. Their social acceptance towards peers with ASD seemed to also improve. In contrast, one study found no positive effect on the social acceptance of pupils with SEN (Hundert \& Houghton, 1992).

\subsection{Group activities}

Half of the studies measuring the effects of group activities on the social participation of children with SEN are experimental or quasi-experimental studies $(n=6)$. The others are single-case studies $(n=6)$. Two intervention strategies were implemented: group activities in the academic context (peer tutoring and cooperative learning), and group activities in the social context (e.g., support groups, interest clubs, group counselling, friendship activities, and structured play). In most studies, the group activities were moderated by teachers alone or in collaboration with the researchers.

Participants: A total of 216 pupils with SEN, aged 3 to 13 years, participated in these studies. The number of participants per study varies from two to 112 . The participants are described as having BD ( $\mathrm{n}=138)$, LD (n $=34), \operatorname{ID}(\mathrm{n}=26), \operatorname{ASD}(\mathrm{n}=15)$, or DD $(\mathrm{n}=3)$.

Interventions: Five studies evaluated the effects of cooperative learning and peer tutoring involving pupils with LD, ID, or ASD and their TD peers (Dugan et al., 1995; Fuchs, Fuchs, Mathes, \& Martinez, 2002; Jacques, Wilton, \& Townsend, 1998; Kamps et al., 1994; Sideridis et al., 1997). For example, in the study of Jacques et al. (1998), cooperative learning groups were implemented for six weeks in several classrooms during geography lessons. Fuchs and his colleagues (2002) studied the effects of peer tutoring in reading classes on the social acceptance and friendships of pupils with LD and their TD peers. Higher-performing pupils were paired with lower-performing pupils during the reading sessions, alternating the role of tutor and tutee.

In seven studies, the group activities were related to social topics. The group interventions involved structured play and friendship activities for pupils with DD and their TD peers (Frea, Craig-Unkefer, Odom, \& Johnson, 1999), interest clubs during lunch or recess in which pupils with ASD and their TD peers were involved in fun activities related to a topic of interest of the pupils with ASD (Koegel, Vernon, Koegel, Koegel, \& Paullin, 2012), weekly therapeutic group counselling for the whole class (Shechtman, 1999), or support groups focused on pupils with BD, LD, or ASD involving their TD peers (Frederickson \& Turner, 2003; Frederickson, Warren, \& Turner, 2005; Kalyva \& Avramidis, 2005). In the study of Frederickson and Turner (2003), support groups called "Circle of Friends" were created to discuss strategies weekly to solve the social problems and help pupils with BD. The study of Hunt, Farron-Davis, Wrenn, Hirose-Hatae, and Goetz (1997) is the only one evaluating a multi-component intervention including (1) information provision on the communication system and adapted curriculum of children with SEN, (2) the use of media to facilitate interactions, and (3) a partner system in which interactions are prompted and promoted by teachers.

Effects: In five studies (two experimental studies and three single-case studies), the implementation of group activities in an academic context involving pupils with ASD, BD, DD, ID, and LD and their TD peers, namely cooperative learning and peer tutoring, had a positive impact on the social interactions and social acceptance of pupils with SEN (Dugan et al., 1995; Fuchs et al., 2002; Jacques et al., 1998; Kamps et al., 1994; Sideridis et al., 1997). Cooperative learning and peer tutoring also positively influenced the academic 
achievement of pupils with and without SEN (Dugan et al., 1995; Kamps et al., 1994; Sideris et al., 1997). Effect sizes for these interventions were not reported.

The effects of group activities in a social context depended of the type of intervention. Findings of three experimental studies suggest that support groups such as the "Circle of Friends" have a positive effect on the social acceptance and social interactions of pupils with ASD, BD, and LD (Frederickson \& Turner, 2003; Frederickson et al., 2005; Kalyva \& Avramidis, 2005). In two of these studies medium to large effect sizes were reported (Frederickson \& Turner, 2003; Frederickson et al., 2005). However, "Circle of Friends" had no significant impact on the perception of pupils with SEN regarding their social acceptance in the peer group (Frederickson \& Turner, 2003). In addition, the positive effects did not seem to last once the "Circle of Friends" was no longer implemented (Frederickson et al., 2005). Interest clubs had a positive effect on interactions with peers during recess for children with ASD, but no effect size was reported (Koegel et al., 2012). A multi-component intervention to foster interactions with pupils with SEN also had a positive effect on interactions, but effect size was not reported (Hunt et al., 1997). Structured play and friendship activities in preschool classrooms, as well as therapeutic group counselling in primary classrooms, did not have a significant positive effect on the social interactions, the social acceptance, and self-perceived social acceptance of pupils with SEN (Frea et al., 1999; Shechtman, 1999).

\subsection{Training of paraprofessionals}

Three of the studies measuring the effects of training paraprofessionals with the goal of increasing the frequency of social interactions between pupils with SEN and their peers are single-case studies (Feldman \& Matos, 2012; Licciardello, Harchik, \& Luiselli, 2008; Malmgren, Causton-Theoharis, \& Trezek, 2005). One of them is an experimental study (Kretzmann, Shih, \& Kasari, 2015).

Participants: These studies involved 34 pupils with SEN, aged 5 to 11 years. The number of target participants varies from three to 24. The participants are described as having ASD $(n=31)$ or BD $(n=3)$.

Intervention: The interventions reported in these studies targeted paraprofessionals who accompanied pupils with ASD or BD. Paraprofessionals received short trainings to learn how to facilitate social interactions between pupils with SEN and their TD peers. The training involved techniques in modelling, triggering, and positive reinforcement to stimulate the initiation and maintenance of social interactions. In a study by Kretzmann et al. (2015), for example, the paraprofessionals received active coaching to learn how to facilitate social interactions between pupils with ASD and their peers.

Effects: Three studies (two single-case studies and one experimental study) showed positive intervention effects of training paraprofessionals on the frequency and/or the quality of the social interactions between pupils with ASD and their TD peers (Feldman \& Matos, 2012; Kretzman et al., 2015; Licciardello et al., 2008). Two studies reported medium to large effect sizes (Kretzman et al., 2015; Licciardello et al., 2008). In contrast, the single-case study conducted with children with BD yielded mixed findings (Malmgren, et al., 2005). The average rate of interactions increased for the three participants, but the low percentage of nonoverlapping data reported by the authors suggests that the intervention had a small positive effect for one participant, and a neutral effect for the other two participants.

\section{Discussion}


The goal of this systematic review was to identify and describe studies assessing the effects of interventions in mainstream preschool and primary classrooms aiming to improve the social participation of included pupils with SEN. Social participation of pupils with SEN has been defined along the four dimensions found by Koster and her colleagues (2009): the social acceptance of pupils with SEN by their peers, their selfperception of their own social acceptance, their social interactions with the peers and their social relationships/friendships with peers.

\subsection{School-based interventions and their effectiveness}

Different types of school-based interventions were identified in this systematic review: teaching interaction strategies to TD pupils, group activities in the academic or social context, and training of paraprofessionals to facilitate social interactions among pupils with ASD, BD, DD, HI, ID, LD, and VI and their TD peers. Although a majority of the studies report a positive impact of interventions, not all intervention types can be regarded as evidence-based. For most of them research is currently insufficient.

Based on the findings of this review, teaching social interaction skills to TD pupils in preschool and primary school classrooms is well documented and can be considered as an evidence-based intervention to improve social interactions among pupils with ASD, BD, DD, and ID and their TD peers. Indeed, several methodologically thorough studies revealed positive effects and reported medium to large effect sizes. This type of intervention also seems to have a positive effect on the social acceptance of children with SEN (Batchelor \& Taylor, 2005; Goldstein et al., 1997; Thiemann \& Goldstein, 1997), but studies are lacking to draw firm conclusions.

Three other intervention types seem to be effective, even if they are not yet sufficiently documented by methodologically thorough studies to be considered evidence-based according to the criteria from the Council of Exceptional Children (2014). First, group activities in the academic context, namely cooperative learning and peer tutoring, were found to have a positive effect on the social acceptance and social interactions of pupils with SEN (Dugan et al., 1995; Fuchs et al., 2002; Jacques et al., 1998; Kamps et al., 1994; Sideridis et al., 1997). Unfortunately, no effect sizes were reported, making it difficult to compare its effectiveness with the other type of interventions. Second, regularly implemented support group meetings (i.e., "Circles of Friends") positively influenced the social acceptance and social interactions of pupils with ASD or BD with medium to large effect sizes (Frederickson \& Turner, 2003; Frederickson et al., 2005; Kalyva \& Avramidis, 2005); however, this positive effect does not seem to last for children with BD once the support group is no longer implemented (Frederickson et al., 2005). The existing research is insufficient to draw conclusions on the effectiveness of other types of group activities in the social context. Third, training and coaching paraprofessionals has a positive effect on social interactions between pupils with ASD and their peers with medium to large effect sizes (Feldman \& Matos, 2012; Kretzmann et al., 2015; Licciardello, et al., 2008). Findings are mixed, however, regarding the effect of this intervention for children with BD (Malmgren et al., 2005).

\subsection{Studies' characteristics}

A first observation that can be drawn from this systematic review relates to the type of school-based interventions. The necessity of involving classmates when implementing interventions to improve the social participation of pupils with SEN in general education classrooms seems to be recognized. All reviewed studies involved the participation of SEN pupils' TD peers. The majority of the researchers even decided to 
involve all classmates in the interventions to ensure the maintenance and generalization of the positive effects. In addition, most of the studies delegated the implementation of interventions to the school staff, such as teachers, classroom assistants, and/or paraprofessionals. Teaching interaction strategies to pupils was by far the most evaluated type of intervention, followed by group activities in the academic or social context. The least investigated type of school-based intervention is the training of paraprofessionals or other members of the school staff to facilitate interactions among pupils with and without SEN. Thus, there is a clear need for increased quantity and quality of research on school-based interventions to foster the social participation of SEN pupils in mainstream classrooms, especially on group activities and training of school staff. The Council for Exceptional Children (2014) offers useful guidelines to plan methodologically sound studies with experimental group comparison designs or single-subject experimental designs. Finally, it could be interesting to further investigate the implementation of group activities in the academic context, namely cooperative learning and peer tutoring. This type of intervention strategy is promising because first, it is inclusive, since all pupils can be involved in the activities, second, academic as well as social positive outcomes can be expected, and third, the implementation is relatively easy and cost-effective.

A second observation is that a majority of the studies were conducted with pupils with ASD. As a consequence, there is a broad knowledge on interventions to foster the social participation of these pupils. However, there are also other groups of pupils with SEN who are included in general education classrooms and need special support with regard to social participation. More intervention studies on different groups of children with SEN are clearly needed.

A third observation is that social interactions are by far the most assessed dimension of social participation for evaluating the effects of school-based interventions to improve the social participation of pupils with SEN. The emphasis on this dimension could be due to the difficulties individuals with SEN face and the fact that the majority of the studies actually involved pupils with ASD, who generally have difficulties interacting with peers (Camargo et al., 2014; Whalon et al., 2015). Another potential reason for the focus on social interactions is that this dimension is perceived as being easier to influence and evaluate than, for example, the self-perception of social acceptance or friendships. Social interactions can certainly be seen as the "basic dimension" when trying to foster the social participation of pupils with SEN. Without social interactions, it is impossible to form social relationships or friendships (Fabes, Martin, \& Hanish, 2009). Although a great number of studies show that pupils with SEN are less accepted and more often rejected by their classmates compared with TD peers, studies evaluating interventions aimed at improving social acceptance are less frequent. The few studies demonstrate that this dimension of social participation can be positively influenced by school-based interventions (Batchelor \& Taylor, 2005; Goldstein et al., 1997; Frederickson \& Turner, 2003; Fuchs et al., 2002; Jacques et al., 1998; Thiemann \& Goldstein, 2004). The two other dimensions of social participation, friendships between SEN pupils and their classmates, and the SEN pupils' selfperception of their social acceptance in the classroom, have been clearly neglected in intervention studies. This is somewhat surprising given the important role of friendships for children's socio-emotional development (Ladd, 1990; Ladd \& Troop-Gordon, 2003). In addition, pupils' self-perception of their social acceptance can be regarded as an aspect of the sense of belonging that has been identified by several researchers as an important part of social participation (Eriksson \& Granlund, 2004; Falkmer et al., 2012; Hammel et al., 2008). This research gap makes it difficult to draw conclusions concerning the types of interventions that could improve the friendships and the self-perception of social acceptance of pupils with SEN. When planning future interventions studies it could be interesting to measure several dimensions of social participation to encompass the multidimensionality of the concept and better understand the social processes influenced by the intervention. 


\subsection{Limitations}

This systematic review has several limitations. First, the definition of social participation by Koster et al. (2009) was used to determine the key words for the search of articles. Only generic terms were used, neglecting the descriptive parameters (e.g., victimization in the dimension of social acceptance). Interesting articles might have been excluded because they did not match the selection criteria (e.g., interventions on social cognition). Second, the inclusion criteria regarding the full membership of pupils with SEN in mainstream classrooms turned out to be challenging. The inclusion practices were not always described in detail in the studies. Third, the results are not representative regarding pupils with SEN as a whole and social participation in general. The findings especially focused on pupils with ASD and the dimension of social interactions.

\subsection{Conclusion}

This review shows that there are various effective strategies to foster the social participation of pupils with SEN in inclusive classrooms. Interestingly, no studies have been conducted in French- and German-speaking countries, and a majority of the reviewed studies were conducted with pupils with ASD. This means that the knowledge on interventions to facilitate social participation tends to be restricted to a specific group of pupils and selected educational systems. If researchers wish to recommend evidence-based intervention strategies, more methodologically sound studies evaluating the effects of interventions on multiple dimensions of social participation of pupils with SEN, especially children with LD, BD, ID or sensory and/or motor impairments, are clearly needed. 


\section{Acknowledgements}

This work was supported by the Swiss National Science Foundation [grant number 146086]. 


\section{References}

Avramidis, E. (2010). Social relationships of pupils with special educational needs in the mainstream primary class: Peer group membership and peer-assessed social behaviour. European Journal of Special Needs Education, 25(4), 413-429. doi:10.1080/08856257.2010.513550

Avramidis, E. (2013). Self-concept, social position and social participation of pupils with SEN in mainstream primary schools. Research Papers in Education, 28(4), 421-442. doi:10.1080/02671522.2012.673006

*Banda, D. R., Hart, S. L., \& Liu-Gitz, L. (2010). Impact of training peers and children with autism on social skills during center time activities in inclusive classrooms. Research in Autism Spectrum Disorders, 4(4), 619-625. doi:10.1016/j.rasd.2009.12.005

*Batchelor, D., \& Taylor, H. (2005). Social inclusion - next step: User-friendly strategies to promote social interaction and peer acceptance of children with disabilities. Australian Journal of Early Childhood, 30(4), 10-18.

Bellini, S., Peters, J. K., Benner, L., \& Hopf, A. (2007). A meta-analysis of school-based social skills interventions for children with autism spectrum disorders. Remedial and Special Education, 28(3), 153-162. doi:10.1177/07419325070280030401

Bierman, K. L., \& Powers, C. J. (2009). Social skills training to improve peer relations. In K. H. Rubin, W. M. Bukowski, \& B. P. Laursen (Eds.), Social, emotional, and personality development in context. Handbook of peer interactions, relationships, and groups (pp. 603-621). New York: Guilford Press.

Bless, G. (2004). Schulische Integration. Kritische Aspekte zu ihrer Realisierung innerhalb der Schweizer Bildungssysteme. In A. Kummer Wyss \& P. Walther-Müller (Eds.), Integration: Anspruch und Wirklichkeit (pp. 41-56). Luzern: Edition SZH/CSPS.

Bossaert, G., Colpin, H., Pijl, S. J., \& Petry, K. (2013). Truly included? A literature study focusing on the social dimension of inclusion in education. International Journal of Inclusive Education, 17(1), 6079. doi:10.1080/13603116.2011.580464

Camargo, S., Rispoli, M., Ganz, J., Hong, E., Davis, H., \& Mason, R. (2014). A review of the quality of behaviorally-based intervention research to improve social interaction skills of children with ASD in inclusive settings. Journal of Autism and Developmental Disorders, 44(9), 2096-2116. doi:10.1007/s10803-014-2060-7

Cambra, C., \& Silvestre, N. (2003). Students with special educational needs in the inclusive classroom: Social integration and self-concept. European Journal of Special Needs Education, 18(2), 197-208. doi:10.1080/0885625032000078989

Chang, Y.-C., \& Locke, J. (2016). A systematic review of peer-mediated interventions for children with autism spectrum disorder. Research in Autism Spectrum Disorders, 27, 1-10. doi:10.1016/j.rasd.2016.03.010

Cohen, J. (1988). Statistical power analysis for the behavioral sciences. London : Routledge.

Council for Exceptional Children (2014). Standards for evidence-based practices in special education. Retrieved from 
http://www.cec.sped.org/ /media/Images/Standards/CEC\%20EBP\%20Standards\%20cover/CECs\%2 0Evidence\%20Based\%20Practice\%20Standards.pdf

*Dugan, E., Kamps, D., Leonard, B., Watkins, N., Rheinberger, A., \& Stackhaus, J. (1995). Effects of cooperative learning groups during social studies for students with autism and fourth-grade peers. Journal of Applied Behavior Analysis, 28(2), 175-188.

Eriksson, L., \& Granlund, M. (2004). Conceptions of participation in students with disabilities and persons in their close environment. Journal of Developmental and Physical Disabilities, 16(3), 229-245. doi:10.1023/B:JODD.0000032299.31588.fd

Estell, D. B., Jones, M. H., Pearl, R., van Acker, R., Farmer, T. W., \& Rodkin, P. C. (2008). Peer groups, popularity, and social preference: Trajectories of social functioning among students with and without learning disabilities. Journal of Learning Disabilities, 41(1), 5-14. doi:10.1177/0022219407310993

Fabes, R. A., Martin, C. L., \& Hanish, L. D. (2009). Children's behaviors and interactions with peers. In K. H. Rubin, W. M. Bukowski, \& B. P. Laursen (Eds.), Social, emotional, and personality development in context. Handbook of peer interactions, relationships, and groups (pp. 45-62). New York: Guilford Press.

Falkmer, M., Granlund, M., Nilholm, C., \& Falkmer, T. (2012). From my perspective: Perceived participation in mainstream schools in students with autism spectrum conditions. Developmental Neurorehabilitation, 15(3), 191-201. doi:10.3109/17518423.2012.671382

*Feldman, E. K., \& Matos, R. (2012). Training paraprofessionals to facilitate social interactions between children with autism and their typically developing peers. Journal of Positive Behavior Interventions, 15(3), 169-179. doi:10.1177/1098300712457421

*Frea, W., Craig-Unkefer, L., Odom, S. L., \& Johnson, D. (1999). Differential effects of structured social integration and group friendship activities for promoting social interaction with peers. Journal of Early Intervention, 22(3), 230-242. doi:10.1177/105381519902200306

Frederickson, N., Simmonds, E., Evans, L., \& Soulsby, C. (2007). Assessing the social and affective outcomes of inclusion. British Journal of Special Education, 34(2), 105-115. doi:10.1111/j.14678578.2007.00463.x

*Frederickson, N., \& Turner, J. (2003). Utilizing the classroom peer group to adress children's social needs: An evaluation of the circle of friends intervention approach. The Journal of Special Education, $36(4), 234-245$.

*Frederickson, N., Warren, L., \& Turner, J. (2005). Circle of Friends: An exploration of impact over time. Educational Psychology in Practice, 21(3), 197-217. doi:10.1080/02667360500205883

Freeman, S. F., \& Alkin, M. C. (2000). Academic and social attainments of children with mental retardation in general education and special education settings. Remedial and Special Education, 21(1), 3-26. doi:10.1177/074193250002100102

Frostad, P., \& Pijl, S. J. (2007). Does being friendly help in making friends? The relation between the social position and social skills of pupils with special needs in mainstream education. European Journal of Special Needs Education, 22(1), 15-30. doi:10.1080/08856250601082224 
*Fuchs, D., Fuchs, L. S., Mathes, P. G., \& Martinez, E. A. (2002). Preliminary evidence on the social standing of students with learning disabilities in PALS and no-PALS classrooms. Learning Disabilities Research \& Practice, 17(4), 205-215. doi:10.1111/1540-5826.00046

Garrote, A. (2016). Soziale Teilhabe von Kindern in inklusiven Klassen. Empirische Pädagogik, 30(1), 6780.

Gifford-Smith, M. E., \& Brownell, C. A. (2003). Childhood peer relationships: Social acceptance, friendships, and peer networks. Journal of School Psychology, 41(4), 235-284. doi:10.1016/S00224405(03)00048-7

*Goldstein, H., \& Cisar, C. L. (1992). Promoting interaction during sociodramatic play: Teaching scripts to typical preschoolers and classmates with disabilities. Journal of Applied Behavior Analysis, 25(2), 265-280.

*Goldstein, H., Kaczmarek, L., Pennington, R., \& Shafer, K. (1992). Peer-mediated intervention: Attending to, commenting on, and acknowledging the behavior of preschoolers with autism. Journal of Applied Behavior Analysis, 25(2), 289-305. doi:10.1901/jaba.1992.25-289

*Goldstein, H., English, K., Shafer, K., \& Kaczmarek, L. (1997). Interaction among preschoolers with and without disabilities: effects of across-the-day peer intervention. Journal of Speech, Language \& Hearing Research, 40(1), 33-48. Retrieved from http://search.ebscohost.com/login.aspx?direct=true \&db=c8h\&AN=1998076502\&site=ehost-live

Grütter, J., Meyer, B., \& Glenz, A. (2015). Sozialer Ausschluss in Integrationsklassen: Ansichtssache? Psychologie in Erziehung und Unterricht, 62(1), 65. doi:10.2378/peu2015.art05d

Hammel, J., Magasi, S., Heinemann, A., Whiteneck, G., Bogner, J., \& Rodriguez, E. (2008). What does participation mean? An insider perspective from people with disabilities. Disability and Rehabilitation, 30(19), 1445-1460. doi:10.1080/09638280701625534

*Harjusola-Webb, S., Hubbell, S. P., \& Bedesem, P. (2012). Increasing prosocial behaviors of young children with disabilities in inclusive classrooms using a combination of peer-mediated intervention and social narratives. Beyond Behavior, 29-36.

*Harper, C. B., Symon, J. B. G., \& Frea, W. D. (2008). Recess is time-in: Using peers to improve social skills of children with autism. Journal of Autism and Developmental Disorders, 38(5), 815-826. doi:10.1007/s10803-007-0449-2

Harrower, J. K., \& Dunlap, G. (2001). Including children with autism in general education classrooms: A review of effective strategies. Behavior Modification, 25(5), 762-784.

Hartzell, R., Gann, C., Liaupsin, C., \& Clem, S. (2015). Increasing social engagement in an inclusive environment. Education and Training in Autism and Developmental Disabilities, 50(3), 264-277.

Hestenes, L. L., \& Carroll, D. E. (2000). The play interactions of young children with and without disabilities: Individual and environmental influences. Early Childhood Research Quarterly, 15(2), 229-246. doi:10.1016/S0885-2006(00)00052-1

Hodges, E. V. E., Boivin, M., Vitaro, F., \& Bukowski, W. M. (2011). The power of friendship: Protection against an escalating cycle of peer victimization. In M. Killen \& R. J. Coplan (Eds.), Social 
development in childhood and adolescence. À contemporary reader (pp. 155-165). Chichester, West Sussex, UK, Malden, MA: Wiley-Blackwell.

Huber, C. (2006). Soziale Integration in der Schule?!: Eine empirische Untersuchung zur sozialen Integration von Schülern mit sonderpädagogischem Förderbedarf im Gemeinsamen Unterricht. Marburg: Tectum-Verlag.

Huber, C., \& Wilbert, J. (2012). Soziale Ausgrenzung von Schülern mit sonderpädagogischem Förderbedarf und niedrigen Schulleistungen im gemeinsamen Unterricht. Empirische Sonderpädagogik, (2), 147 165.

*Hundert, J., \& Houghton, A. (1992). Promoting social interaction of children with disabilities in integrated preschools: A failure to generalize. Exceptional Children, 58, 311-320.

Hundert, J., Rowe, S., \& Harrison, E. (2014). The combined effects of social script training and peer buddies on generalized peer interaction of children with ASD in inclusive classrooms. Focus on Autism and Other Developmental Disabilities, 29(4), 206-215. doi:10.1177/1088357614522288

*Hunt, P., Farron-Davis, F., Wrenn, M., Hirose-Hatae, A., \& Goetz, L. (1997). Promoting interactive partnerships in inclusive educational settings. Journal of the Association for Persons with Severe Handicaps, 22(3), 127-137.

*Jacques, N., Wilton, K., \& Townsend, M. (1998). Cooperative learning and social acceptance of children with mild intellectual disability. Journal of Intellectual Disability Research, 42(1), 29-36. doi:10.1046/j.1365-2788.1998.00098.x

*Kalyva, E., \& Avramidis, E. (2005). Improving communication between children with autism and their peers through the 'circle of friends': A small-scale Intervention Study. Journal of Applied Research in Intellectual Disabilities, 18(3), 253-261. doi:10.1111/j.1468-3148.2005.00232.x

*Kamps, D. M., Barbetta, P. M., Leonard, B. R., \& Delquadri, J. (1994). Classwide peer tutoring: An integration strategy to improve reading skills and promote peer interactions among students with autism and general education peers. Journal of Applied Behavior Analysis, 27(1), 49-61. doi:10.1901/jaba.1994.27-49

*Kamps, D. M., Leonard, B. R., Vernon, S., Dugan, E. P., Delquadri, J. C., Gershon, B., et al. (1992). Teaching social skills to students with autism to increase peer interactions in an integrated first-grade classroom. Journal of Applied Behavior Analysis, 25(2), 281-288. doi:10.1901/jaba.1992.25-281

Kamps, D., Royer, J., Dugan, E., Kravits, T., Gonzalez-Lopez, A., Garcia, J., et al. (2002). Peer training to facilitate social interaction for elementary students with autism and theirs peers. Council for Exceptional Children, 68(2), 173-187.

*Kamps, D., Thiemann-Bourque, K., Heitzman-Powell, L., Schwartz, I., Rosenberg, N., Mason, R., \& Cox, S. (2015). A comprehensive peer network intervention to improve social communication of children with autism spectrum disorders: a randomized trial in kindergarten and first grade. Journal of Autism and Developmental Disorders, 45(6), 1809-1824. doi:10.1007/s10803-014-2340-2

Kasari, C., Locke, J., Gulsrud, A., \& Rotheram-Fuller, E. (2011). Social networks and friendships at school: comparing children with and without ASD. Journal of Autism and Developmental Disorders, 41(5), 533-544. doi:10.1007/s10803-010-1076-x 
*Katz, E., \& Girolametto, L. (2013). Peer-mediated intervention for preschoolers with ASD implemented in early childhood education settings. Topics in Early Childhood Special Education, 33(3), 133-143. doi:10.1177/0271121413484972

Kavale, K. A., \& Forness, S. R. (1996). Social skill deficits and learning disabilities: A meta-analysis. Journal of Learning Disabilities, 29(3), 226-237. doi:10.1177/002221949602900301

Kavale, K. A., \& Mostert, M. P. (2004). Social skills interventions for individuals with learning disabilities. Learning Disability Quarterly, 27, 31-43.

Kemp, C., \& Carter, M. (2002). The social skills and social status of mainstreamed students with intellectual disabilities. Educational Psychology, 22(4), 391-411. doi:10.1080/0144341022000003097

*Koegel, L. K., Vernon, T. W., Koegel, R. L., Koegel, B. L., \& Paullin, A. W. (2012). Improving social engagement and initiations between children with autism spectrum disorder and their peers in inclusive settings. Journal of Positive Behavior Interventions, 14(4), 220-227. doi:10.1177/1098300712437042

*Kohler, F. W., Greteman, C., Raschke, D., \& Highnam, C. (2007). Using a buddy skills package to increase the social interactions between a preschooler with autism and her peers. Topics in Early Childhood Special Education, 27(3), 155-163.

Koster, M., Nakken, H., Pijl, S. J., \& van Houten, E. (2009). Being part of the peer group: A literature study focusing on the social dimension of inclusion in education. International Journal of Inclusive Education, 13(2), 117-140. doi:10.1080/13603110701284680

Koster, M., Pijl, S. J., Nakken, H., \& van Houten, E. (2010). Social participation of students with special needs in regular primary education in the Netherlands. International Journal of Disability, Development and Education, 57(1), 59-75. doi:10.1080/10349120903537905

*Kretzmann, M., Shih, W., \& Kasari, C. (2015). Improving peer engagement of children with autism on the school playground: a randomized controlled trial. Behavior Therapy, 46(1), 20-28. doi:10.1016/j.beth.2014.03.006

Krull, J., Wilbert, J., \& Hennemann, T. (2014). Soziale Ausgrenzung von Erstklässlerinnen und Erstklässlern mit sonderpädagogischem Förderbedarf im Gemeinsamen Unterricht. Empirische Sonderpädagogik, 6(1), 59-75.

Ladd, G. W. (1990). Having friends, keeping friends, making friends, and being liked by peers in the classroom: Predictors of children's early school adjustment? Child Development, 61(4), 1081-1100. Retrieved from 10.1111/1467-8624.ep9102040965

Ladd, G. W., \& Troop-Gordon, W. (2003). The role of chronic peer difficulties in the development of children's psychological adjustment problems. Child Development, 74(5), 1344-1367. Retrieved from 10.1111/1467-8624.00611

*Licciardello, C. C., Harchik, A. E., \& Luiselli, J. K. (2008). Social skills intervention for children with autism during interactive play at a public elementary school. Education \& Treatment of Children, 31(1), 27-37. Retrieved from http://search.ebscohost.com/login.aspx ?direct=true\&db=sih\&AN=29968955\&site=ehost-live 
*Malmgren, K. W., Causton-Theoharis, J. N., \& Trezek, B. J. (2005). Increasing peer interactions for students with behavioral disorders via paraprofessional training. Behavioral Disorders, 31(1), 95106. doi: $10.2307 / 23890403$

*Mason, R., Kamps, D., Turcotte, A., Cox, S., Feldmiller, S., \& Miller, T. (2014). Peer mediation to increase communication and interaction at recess for students with autism spectrum disorders. Research in Autism Spectrum Disorders, 8(3), 334-344. doi:10.1016/j.rasd.2013.12.014

McConnell, S. R. (2002). Interventions to facilitate social interaction for young children with autism: Review of available research and recommendations for educational intervention and future research. Journal of Autism and Developmental Disorders, 32(5), 351-372. doi:10.1023/A:1020537805154

McFadden, B., Kamps, D., \& Heitzman-Powell, L. (2014). Social communication effects of peer-mediated recess intervention for children with autism. Research in Autism Spectrum Disorders, 8(12), 16991712. doi:10.1016/j.rasd.2014.08.015

*McGrath, A. M., Bosch, S., Sullivan, C. L., \& Fuqua, R. W. (2003). Training reciprocal social interactions between preschoolers and a child with autism. Journal of Positive Behavior Interventions, 5(1), 47 54.

Monchy, M. de, Pijl, S. J., \& Zandberg, T. (2004). Discrepancies in judging social inclusion and bullying of pupils with behaviour problems. European Journal of Special Needs Education, 19(3), 317-330. doi:10.1080/0885625042000262488

Nadeau L., \& Tessier R. (2003). Relations sociales entre enfants à l'âge scolaire: effet de la prématurité et de la déficience motrice. Enfance, 55(1), 48-55. doi: 10.3917/enf.551.0048

*Nelson, C., McDonnell, A. P., Johnston, S. S., Crompton, A., \& Nelson, A. R. (2007). Keys to play: A strategy to increase the social interactions of young children with autism and their typically developing peers. Education and Training in Developmental Disabilities, 42(2), 165-181.

Nepi, L. D., Fioravanti, J., Nannini, P., \& Peru, A. (2015). Social acceptance and the choosing of favourite classmates: a comparison between students with special educational needs and typically developing students in a context of full inclusion. British Journal of Special Education, n/a. doi:10.1111/14678578.12096

Nowicki, E. A. (2003). A meta-analysis of the social competence of children with learning disabilities compared to classmates of low and average to high achievement. Learning Disability Quarterly, 26(3), 171-188.

Odom, S. L., \& Diamond, K. E. (1998). Inclusion of young children with special needs in early childhood education: The research base. Early Childhood Research Quarterly, 13(1), 3-25.

*Owen-DeSchryver, J. S., Carr, E. G., Cale, S. I., \& Blakeley-Smith, A. (2008). Promoting social interactions between students with autism spectrum disorders and their peers in inclusive school settings. Focus on Autism and Other Developmental Disabilities, 23(1), 15-28. doi:10.1177/1088357608314370

Peters, E., Riksen-Walraven, J. M., Cillessen, A. H. N., \& Weerth, C. de. (2011). Peer rejection and HPA activity in middle childhood: Friendship makes a difference. Child Development, 82(6), 1906-1920. Retrieved from 10.1111/j.1467-8624.2011.01647.x 
*Pierce, K., \& Schreibman, L. (1997). Multiple peer use of pivotal response training to increase social behaviors of classmates with autism: results from trained and untrained peers. Journal of Applied Behavior Analysis, 30(1), 157-160. doi:10.1901/jaba.1997.30-157

Pijl, S. J., \& Frostad, P. (2010). Peer acceptance and self-concept of students with disabilities in regular education. European Journal of Special Needs Education, 25(1), 93-105. doi:10.1080/08856250903450947

Pijl, S. J., Frostad, P., \& Flem, A. (2008). The social position of pupils with special needs in regular schools. Scandinavian Journal of Educational Research, 52(4), 387-405. doi:10.1080/00313830802184558

Pijl, S. J., Skaalvik, E. M., \& Skaalvik, S. (2010). Students with special needs and the composition of their peer group. Irish Educational Studies, 29(1), 57-70. doi:10.1080/03323310903522693

Quinn, M. M., Kavale, K. A., Mathur, S. R., Rutherford, R. B., \& Forness, S. R. (1999). A meta-analysis of social skill interventions for students with emotional or behavioral disorders. Journal of Emotional and Behavioral Disorders, 7(1), 54-64. doi:10.1177/106342669900700106

Rotheram-Fuller, E., Kasari, C., Chamberlain, B., \& Locke, J. (2010). Social involvement of children with autism spectrum disorders in elementary school classrooms. Journal of Child Psychology and Psychiatry, 51(11), 1227-1234. doi:10.1111/j.1469-7610.2010.02289.x

Ruijs, N. M., \& Peetsma, T. T. D. (2009). Effects of inclusion on students with and without special educational needs reviewed. Educational Research Review, 4(2), 67-79. doi:10.1016/j.edurev.2009.02.002

Scheepstra, A. J. M., Nakken, H., \& Pijl, S. J. (1999). Contacts with classmates: the social position of pupils with Down's syndrome in Dutch mainstream education. European Journal of Special Needs Education, 14(3), 212-220. doi:10.1080/0885625990140303

Schwab, S., Gebhardt, M., Krammer, M., \& Gasteiger-Klicpera, B. (2015). Linking self-rated social inclusion to social behaviour. An empirical study of students with and without special education needs in secondary schools. European Journal of Special Needs Education, 30(1), 1-14. doi:10.1080/08856257.2014.933550

Scruggs, T. E., \& Mastropieri, M. A. (1998). Summarizing Single-Subject Research: Issues and Applications. Behavior Modification, 22(3), 221-242. doi:10.1177/01454455980223001

*Shechtman, Z. (1997). Enhancing social relationships and adjusting behavior in the Israeli classroom. The Journal of Educational Research, 91(2), 99-107. doi:10.1080/00220679709597527

*Sideridis, G. D., Utley, C., Greenwood, C., Delquadri, J., Dawson, H., Palmer, P., \& Reddy, S. (1997). Classwide Peer Tutoring: Effects on the spelling performance and social interactions of students with mild disabilities and their typical peers in an integrated instructional setting. Journal of Behavioral Education, 7, 435-462.

Simeonsson, R. J., Carlson, D., Huntington, G. S., Sturtz McMillen, J., \& Brent, J. L. (2001). Students with disabilities: a national survey of participation in school activities. Disability and Rehabilitation, 23(2), 49-63. doi:10.1080/096382801750058134 
Soodak, L. C., \& McCarthy, M. R. (2006). Classroom management in inclusive settings. In C. M. Evertson \& C. S. Weinstein (Eds.), Handbook of classroom management. Research, practice, and contemporary issues (pp. 461-489). Mahwah, N.J.: Lawrence Erlbaum Associates.

Stanton-Chapman, T. L., \& Brown, T. S. (2015). A strategy to increase the social interactions of 3-year-old children with disabilities in an inclusive classroom. Topics in Early Childhood Special Education, 35(1), 4-14. doi:10.1177/0271121414554210

Stanton-Chapman, T. L., \& Snell, M. E. (2011). Promoting turn-taking skills in preschool children with disabilities: The effects of a peer-based social communication intervention. Early Childhood Research Quarterly, 26(3), 303-319. doi:10.1016/j.ecresq.2010.11.002

*Storey, K., Smith, D. J., \& Strain, P. S. (1993). Use of classroom assistants and peer-mediated intervention to increase integration in preschool settings. Exceptionality, 4(1), 1-16. doi:10.1207/s15327035ex0401_1

*Thiemann, K. S., \& Goldstein, H. (2004). Effects of peer training and written text cueing on social communication of school-age children with pervasive developmental disorder. Journal of Speech Language and Hearing Research, 47(1), 126. doi:10.1044/1092-4388(2004/012)

United Nations (2006). Convention on the rights of persons with disabilities and optional protocol. New York: United Nations.

Walker, S. (2007). The social participation of young children with developmental disabilities in inclusive early childhood programs. Electronic Journal for Inclusive Education, 2(2).

Watkins, L., O'Reilly, M., Kuhn, M., Gevarter, C., Lancioni, G. E., Sigafoos, J., \& Lang, R. (2015). A review of peer-mediated social interaction interventions for students with autism in inclusive settings. Journal of Autism and Developmental Disorders, 45(4), 1070-1083. doi:10.1007/s10803014-2264-x

Whalon, K. J., Conroy, M. A., Martinez, J. R., \& Werch, B. L. (2015). School-based peer-related social competence interventions for children with autism spectrum disorder: A meta-analysis and descriptive review of single case research design studies. Journal of Autism and Developmental Disorders, 45(6), 1513-1531. doi:10.1007/s10803-015-2373-1

Yude, C., Goodman, R., \& McConachie, H. (1998). Problems of children with hemiplegia in mainstream primary schools. Journal of Child Psychology and Psychiatry, 39(4), 533-541. doi:10.1111/14697610.00349 